\title{
Testing and Validation of the Questionnaire Identification of Professional Stress Syndrome in Health Workers (IPSSHM)
}

\section{Cătălina Croitoru ${ }^{1}$, Vlada Furdui ${ }^{2}$, Ana Leorda ${ }^{2}$, Anatolie Baciu ${ }^{2}$, Olga Bulat $^{2}$, Ludmila Ursu ${ }^{2}$, Vasile Dumitraș ${ }^{1}$ and Elena Ciobanu ${ }^{1 *}$}

${ }^{1}$ Nicolae Testemitanu State University of Medicine and Pharmacy, Republic of Moldova

${ }^{2}$ Institute of Physiology and Sanocreatology, Republic of Moldova

*Corresponding Author: Elena Ciobanu, Nicolae Testemitanu State University of Medicine and Pharmacy, Republic of Moldova.
Received: July 16, 2021

Published: July 22, 2021

(C) All rights are reserved by Elena Ciobanu., et al.

\section{Abstract}

Introduction: Burnout is a common problem, especially in people whose professional activity is associated with communication with other people. At the WHO European Conference, it was mentioned that work-related stress is a significant problem for about a third of people in European Union countries.

Materials and Methods: A descriptive study was performed. Specialty scientific papers on the indicators that reflect the stress and burnout were consulted for the elaboration of the working tool (IPSSHM questionnaire - for diagnosing the professional stress syndrome in the health workers) and selecting the testing methodology.

Results: A questionnaire, which includes two parts (general and special), was elaborated. The general part of the questionnaire (with ten items) allowed to collect personal social, professional, and married data about the respondent, regarding age, biological gender, family situation, living environment, activity environment, medical specialty, place/work institution, work experience, and information about a part-time job. The unique part of the questionnaire represents a set of 131 items, which characterize the respondent through the prism of six distinctive structural blocks: emotional-sentimental, behavioral block, cognitive block, communicative block, individual-semantic block, and neurophysiological block. The questions in the questionnaire were randomly ordered. The respondent selected the pre-set answers: Yes, No, I didn't think/Differently. Each answer receives a score from 1 to 3, depending on the peculiarity of the question and block belonging. Cronbach's alpha coefficient was 0.71 . The results of the elaborated instrument were compared with the results of two standardized questionnaires (Maslach and Eysenck), which were conducted in parallel.

Conclusion: The obtained results demonstrate the validity of the questionnaire and the possibility of its application identifying health workers' burnout.

Keywords: Questionnaire; Validation; Doctors; Stress; Burnout; Health

\section{Introduction}

Burnout has reached rampant levels among world healthcare professionals, with over one-half of physicians and one-third of nurses experiencing symptoms. The burnout epidemic is detrimental to patient care and may exacerbate the impending physician shortage. 
The extent to which the phenomenon of emotional exhaustion got into our lives is convincingly proven by its presence in artworks from ancient times. The term burnout was introduced in 1974 by American psychologist Herbert Freudenberger, who borrowed it from Graham Greene's "A Burnt-Out Case," dedicated to Dr. Michel Lech, a physician at a leper colony in Yonda, Africa. Cases like burnout were described by poets and prose writers long before Graham Greene and before the emergence of the corresponding scientific concept [1]. In artistic literature, in XIX and XX century European classics works, there are several essentially similar conditions descriptions. For example, Thomas Mann, Nobel Laureate, in his novel Buddenbrooks (1901), depicts Senator Thomas Buddenbrook in such a way that we see the classic symptoms of exhaustion [2]. This phenomenon is reflected in the works of D. London. A.P. Chekhov made a brilliant description of burnout syndrome to doctors in his stories "Ward No. 6" (1892) and "Ionych" (1898) at the end of the 19th century. He managed to draw precisely an image of the characteristic disorders of exhaustion, which, almost 80 years later, were reproduced in scientific terms by foreign psychologists and psychiatrists $[3,4]$. The figurative expression of D. Glauberman (2004), the phenomenon of "burning" in recent decades began to spread with the speed of forest fires [5].

The scientific research shows that over 1500 articles dedicated to the study of various aspects of this phenomenon have been published in the last decade [6-10].

Emotional exhaustion syndrome is characterized by mental fatigue, emotional exhaustion, and symptoms of depression. Emotional supersaturation, accompanied by dynamic failure, aggressive reactions, anger outbursts is observed at the beginning, being replaced by emotional resources decrease and emotional interest loss in the surrounding reality. There is often depersonalization, which means dehumanization (devaluation) of interpersonal relationships, negativity, cynicism towards the feelings and experiences of other people. The individual develops latent or explicit negative attitudes, contacts' impersonality and formality increase, frequent irritation, and conflict situations outbursts. The loss of mental processes emotional component is important (loss of feelings for the loved ones, low empathy - receptivity, complicity) for all the characteristics of depersonalization. The reduction of personal achievements characterizes employee's professional efficiency decrease, which can manifest in negativism towards job merits and opportunities, limiting responsibilities in relation to the social environment, reducing the importance of the carried-out activities. The feeling of one's failure and incompetence is clearly expressed [11-13].

Burnout syndrome is officially recognized in medicine and is included in the International Classification of Diseases ICD-10: 273 - Problems related to the difficulty of organizing one's way of life. The development of "Burnout" syndrome depends on external and internal factors. The group of external factors includes the environmental conditions, work content, and socio-psychological conditions of activity. Out of these, the dominant role in the development of "Burnout" syndrome is played by: destabilizing organization of activities (incorrect organization and planning of work, lack of equipment, poorly structured and vague information); increased responsibility for the performed functions and the result of the work; an unfavourable psychological atmosphere of professional activity; a psychologically complex contingent that a specialist deals with (among teachers and educators, these are children with abnormalities of character, nervous system and mental retardation; doctors have severe, incurable patients, etc.). Internal factors that cause exhaustion include a tendency to emotional rigidity; intense perception and experience of the circumstances of the professional activity (this psychological phenomenon occurs in people with increased responsibility for the task entrusted to them); poor motivation for emotional return to work; moral defects and personality disorientation [11,13-15].

It should be noted that these symptoms are not completely independent of each other but are in a relationship of interconnection and mutual influence, forming larger hierarchical structures, designated as "Burnout" factors. It is proposed that the structural and functional aspect of the problem analysis be considered in all levels: emotional, cognitive, motivational, behavioral, and somatic manifestations $[13,14]$.

The first step in studying a problem is to estimate it correctly and in time. The most common diagnostic technique is based on the three-factor model of professional burning, formulated by psychologist C. Maslach: 1) emotional exhaustion (EE); 2) depersonalization (DP); 3) personal achievement reduction (PAR). The technique is represented by a questionnaire designed to diagnose the professional syndrome "Burnout" [10,16-19]. 


\section{Purpose of the Study}

To elaborate a questionnaire, to identify professional exhaustion phenomenon and to highlight the psychophysiological characteristics of doctors of different specialties.

\section{Materials and Methods}

A pilot study was organized for the elaboration, testing, and adjustment of a questionnaire to identify the phenomenon of burnout and psychophysiological characteristics in doctors of different specialties.

The working tool: questionnaire "Identification of professional stress syndrome in health workers" (IPSSHM).

A descriptive study was performed. Specialty scientific papers were consulted on the indicators that reflect stress and burnout for the elaboration of the questionnaire [18-22].

The original protocol for the elaboration, testing, and validation of the questionnaire included the following steps:

- Study of the specialized bibliographic sources.

- Study and analyze the existing questionnaires in the approached field at the national and international levels. The elaboration of the instrument was based on Maslach (determination of Burnout syndrome) and Eysenck (determination of temperament type) questionnaires.

- Estimation of the modalities that reflect the sanogenicity/ dissanogenicity of each constituent block of mental health.

- Elaboration and adaptation of items on blocks. Stress indicators for each block, were identified and items were formulated to reflect the presence of occupational stress among medical specialists - the first revision of the material in the group of researchers: analysis and discussion of problematic items.

- Modification and adjustment of items after the first revision.

- Discussing the items in a larger group of researchers, with the invitation of an international expert: the second revision of the questionnaire discussion, analysis, adjustment, and stylistic writing of items.

- Discussion of the results of the expert group in the initial group of researchers. The last revision (the third) and the final variant set.
- $\quad$ Obtaining the positive opinion of the Ethics Committee of the State University of Medicine and Pharmacy "Nicolae Testemitanu" from 24.11.2020, no. 1.

- $\quad$ Testing the internal validity of the questionnaire.

- $\quad$ Carrying out a pilot study, applying the questionnaire on a sample of 109 health workers who activate in the medical institutions from the Republic of Moldova.

- Analysis of respondents' proposals on some items, which were difficult or confusing, reformulation and adjustment of these items from their point of view.

The evaluation of the answers is based on the accumulated scores for each question, which in turn are grouped in the constituent blocks of the questionnaire. For each block, the instrument allows estimating the sanogenic, satisfactory and dissanogenic conditions:

- Behavioural block: 15-25 - dissanogenic condition, 26-36 satisfactory condition, 37-45 - sanogenic.

- Emotional-sentimental block: 33-55 - dissanogenic condition, 56-78 - satisfactory condition, 79-99 - sanogenic condition.

- Cognitive block: 16-27 - dissanogenic state, 28-39 - satisfactory condition, 40-48 - sanogenic condition.

- $\quad$ Communicative block: 23-38 - dissanogenic condition, 3954 - satisfactory condition, 55-69 - sanogenic condition.

- Individual-semantic block: 22-37 - dissanogenic condition, 38-53 - satisfactory condition, 54-66 - sanogenic condition.

- Neurophysiological block: 15-25 - dissanogenic condition, 26-35 - satisfactory condition, 36-45 - sanogenic condition.

Thus, based on the accumulated score, this tool allows us to estimate the level of burnout: 125-209 - burnout; 210-294 - satisfactory condition; 295-375 - sanogenic condition.

\section{Results}

Elaboration of the questionnaire

The process of questionnaire elaboration started with the study of the specialty literature to prove the need to initiate the study and the correct choice of the target group, and the choice of the method to reach the targeted respondents. The process of formulating the content of the questions followed. The questions were put in a logi- 
cal order and meaningful format. Then, the length of the questionnaire was checked (Figure 1).

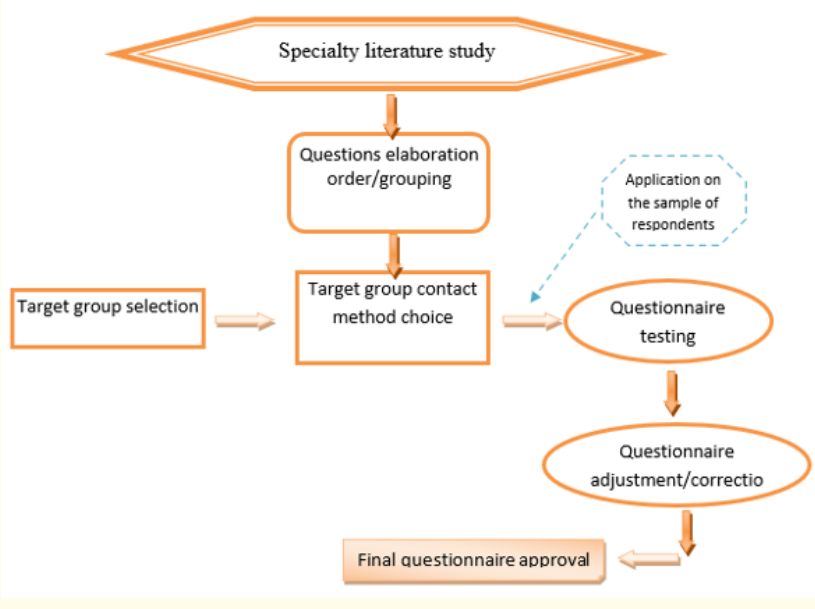

Figure 1: Questionnaire algorithm elaboration.

After applying the questionnaire, nine items were removed, one item was added, and six items were modified. The final survey form included 131 items.

The method of applying the questionnaire in the pilot study was done online through the Google Meet application.

Two methods tested the questionnaire. The first method highlighted the internal consistency of the items, using the Cronbach alpha coefficient (inter-item correlation). The test showed a Cronbach alpha coefficient of 0.71 .

The second method of testing the working tool was to compare the elaborated questionnaire with two standardized questionnaires (Maslach and Eysenck). The fact that $86.3 \%$ of respondents had the same results for all three questionnaires when comparing the results confirms the positive effects of the pilot study.

\section{Characteristics of the questionnaire}

The elaborated questionnaire reflects the changes of all the constitutive components of mental health (neurophysiological, emotional-sentimental, cognitive, communicative, behavioral, and individual-semantic). Consequently, a questionnaire that includes two parts was obtained: the general part with ten items and the special part with 131 items. The general part of the questionnaire allows us to collect personal data (social, professional, and matrimonial) about the respondent, with reference to age, biological gender, family situation, living environment, activity environment, medical specialty, place/work institution, work experience, and information about a part-time job. The special part of the questionnaire characterizes the respondent in terms of six structurally distinctive blocks. Still, the items in the questionnaire are randomly represented: emotional-sentimental block, behavioral block, cognitive block, communicative block, individual-semantic block, and neurophysiological block. The respondent selects the pre-set answers: Yes, No, I didn't think/Differently. Each answer gets a score from 1 to 3, depending on the specifics of the question and block belonging.

Indicators of constitutive block dysanogenies

- Emotional block: Subject's inherent emotionality unmotivated change; irrational concern increase; loneliness feeling prevalence; gloominess and pessimism; anxiety, irritability, emotional duress; unmotivated sadness. According to the accumulated score, 31 (28.4\%) health workers had a dissanogenic conditions, and 78 (71.6\%) - satisfactory conditions.

- Behavioral block: Unmotivated change in the subject's behavior: alcohol, tobacco or gambling addiction, suicidal impulses, unmotivated aggression, antisocial behavior, cynical attitude towards patients. The accumulated score was: 3 (2.7\%) - satisfactory conditions, 106 (97.3\%) - sanogenic conditions.

- Cognitive block: Loss of interest in new theories and ideas at the workplace, alternative approaches to problem-solving, boredom, sadness, preference for standard patterns, routine, to the detriment of creative approach, cynicism or indifference to innovation; little participation or refusal to participate in development experiments - training, education; formal execution of work, memory impairment, speech errors, stiffness and thought patterns. The accumulated score was: 81 (74.3\%) - satisfactory conditions, $1(0.9 \%)$ - sanogenic conditions and 27 (24.8\%) - dissanogenic conditions.

- Communicative block: Low social activity, decreased interest in leisure, hobbies; social contacts are limited at work, few relationships at work and at home, the feeling of isolation, lack of understanding of others and from others, the feeling of lack of support from family, friends, colleagues, low social 
activity, the appearance of speech errors, a decrease of the literacy level, unmotivated decrease in the inherent sociability of the subject, feeling of isolation, lack of understanding of others and from others, feeling of lack of support from family, friends, colleagues. The accumulated score was: 91 (83.5\%) satisfactory conditions, $1(0.9 \%)$ - sanogenic conditions and 17 (15.6\%) - dissanogenic conditions.

- The individual-semantic block: Work, life interest decrease; collision emergence between the ideal and real approach of the world; disappointment in one's activities and personal life problems increase, incorrect self-esteem, decreased interest in hobbies, helplessness, vital "inability," feeling of inferiority towards other people, decreased interest in work, in life in general, vision collisions on the ideal real-world, strong feelings of guilt, self-blame, disappointment in one's own activities, decreased interest in work, in life in general, personal life problems increase. The accumulated score was: 48 (44.0\%) satisfactory conditions, 43 (39.4\%) - sanogenic conditions and 18 (16.5\%) - dissanogenic conditions.

- Neurophysiological block: Sleep disorders, common ailments (headaches, poor general health; high blood pressure; ulcers and inflammatory skin diseases; diseases of the cardiovascular system), food indifference, excessive use of medicines, fatigability, unmotivated weight changes. The accumulated score was: 27 (24.8\%) - satisfactory conditions, 82 (75.2\%) - sanogenic conditions.

As the questionnaire was also intended to determine the type of respondent's behavior, appropriate questions were included. In addition, the questionnaire included questions designed to assess the respondent's sincerity.

In order to verify the veracity of the answers in the elaborated questionnaire, two questionnaires were used in parallel: the Maslach test (diagnosis of burnout) and the Eysenck test (determination of temperament type).

\section{Discussion}

The indicators that reflect stress and burnout, which persist for more than six weeks, assume the presence of professional stress [20-22].

The prevention of professional exhaustion phenomenon is a current and very important aspect as it is registered very fre- quently in all professional fields [13,21,23]. But concrete prevention measures can be applied only when the factors causing the problem, the conditions of manifestation, the amplitude of the effects are well known. One of the effective methods in confirming the presence of burnout and establishing the factors that cause it is the application of psychophysiological tests and hygienic-social questionnaires.

No survey can be successful without a well-designed questionnaire. Unfortunately, the design of the questionnaire has no theoretical basis to guide the researcher in developing an impeccable questionnaire. All that can guide the researcher is a long list of things to do and a list of things not to do, taken from the experience of other researchers in the past and present. Therefore, the design of the questionnaire is more of an art than a science.

Depending on the purpose of the research and the expected purposes, standardized tests/questionnaires can be used, but much more effective are the questionnaires developed specifically for the initiated research. Thus, the questionnaire "Identification of professional stress syndrome in health workers" (IPSSHM) was designed.

Fast and efficient information about a large sample of people can be obtained with the help of the elaborated questionnaire. One problem with the questionnaire is that the respondent may lie because of social desire, i.e., respondents would like to express themselves by telling lies or exaggerating. The researcher must consider the participant's level in designing his question to match the level of education, age, ethnicity, social class, etc. [24].

Before the main study, it is recommended to initiate a pilot study, which helps the researcher by studying small groups so that the correction of the questionnaire can be made, which makes it valid $[1,24]$.

The initiation of a questionnaire has two key stages. The first of these is to articulate the questions that the research is intended to address. The second step is to determine the hypotheses around which the questionnaire is to be designed.

\section{Conclusion}

1. The validation and testing of the questionnaire in the pilot study made it possible to obtain a good tool for identifying burnout in healthcare professionals, initiating measures to 
prevent stress and burnout, and maintaining healthcare workers' health.

2. The questionnaire "Identification of professional stress syndrome in health workers (IPSSHM)" is the first complex tool developed at the national level, which aims at a methodical and multilateral assessment of the emotional exhaustion syndrome of health workers.

3. The verification of the instrument with the reference questionnaires (Eysenck and Maslach) and the calculation of the internal consistency coefficient - Cronbach alpha-is an argument in favour of the stability and reliability of the developed instrument.

4. Expertise, validation, and testing of the instrument provide sufficient consistency and credibility to be used in larger sample studies. These valuable results, from an empirical point of view, fundaments the reliable use of the questionnaire to assess the level of burnout among medical staff.

\section{Conflict of Interests}

The authors declare no conflicts of interest.

\section{Ethical Approval}

The study was approved by the Ethics Committee of the Nicolae Testemitanu State University of Medicine and Pharmacy from the Republic of Moldova, dated 24.11.2020, no. 1.

\section{Research Funding}

The study was carried out within the joint research project of the Francophone University Agency and the Ministry of Education, Culture and Research of the Republic of Moldova on "The international research strengthening capacity of the determinants in behavior and activity of healthcare workers" (2020).

\section{Bibliography}

1. Fontes FF and Herbert J. "Freudenberger e a constituição do burnout como síndrome psicopatológica”. Memorandum (2020): 37.

2. Britannica TE of E. "Buddenbrooks". Encyclopedia Britannica (2020).

3. Chekhov A. "Ward No. 6". (1892): 32.
4. Chekhov A. "Ionych". (1898): 10.

5. Глауберман Д. Радость сгорания. Как конец света может стать новым началом (2004): 384.

6. Pruteanu LM. Stresul ocupaţional şi satisfacţia faţă de locul de muncă în rândul asistenţilor medicali. In: Yearbook of Petre Andrei University Iasi (2014).

7. “Coping with stress at work" (2018).

8. Liu M., et al. "Perceived stress among Macao nursing students in the clinical learning environment". International Journal of Nursing Sciences 2.2 (2015): 128-133.

9. Bahri Yusoff MS and Rahman A. "Stress management for medical students: A systematic review". In: Azcarate, MALV (ed) Social sciences and humanities: applications and theories. InTech (2012): 23.

10. Aslam HD., et al. "Analysis of the level of stress among doctors in public and private hospitals of Pakistan". International Journal of Learning and Development 3.2 (2014): 109-135.

11. Kamoun S. "Le stress au travail, un enjeu de santé". Relations Industrielles 73.2 (2018): 4.

12. Russu-Deleu R., et al. "Evaluarea stresului profesional în rândul medicilor de familie". Sănătate Publică Econ şi Manag în Med 82.4 (2019): 161-168.

13. Yates SW. "Physician stress and burnout." American Journal of Medicine 133.2 (2020): 160-164.

14. Hocine MN., et al. "How to identify and prioritize psychosocial factors impacting stress level”. PLoS One (2016): 1-11.

15. Kosheleva EY., et al. "Stress factors among international and domestic students in Russia". Procedia - Social and Behavioral Sciences 200 (2015): 460-466.

16. Schaufeli WB., et al. "Burnout: 35 years of research and practice”. Career Development International 14.3 (2009): 204-220.

17. Maslach C., et al. "Maslach Burnout Inventory". In: Evaluating stress: A book of resources (1997): 191-218.

18. Borisova DP and Dvoryanchikov NV. "Interdependence of emotional Burnout syndrome and deviant behaviour among employees of penal system". Psychology Law 9.2 (2019): 3953. 
19. Moreno-Jiménez B., et al. "The physician burnout questionnaire: A new definition and measure”. 19.4 (2012): 325-344.

20. Garcia GPA and Marziale MHP. "Indicators of burnout in Primary Health Care workers". Revista Brasileira de Enfermagem 71 (2018): 2334-2342.

21. Kumar S. "Burnout and doctors: prevalence, prevention and intervention". Healthcare 37.4 (2016): 1-9.

22. Olson KD. "Physician Burnout-A Leading indicator of health system performance?" Mayo Clinic Proceedings 92.11 (2017): 1608-1611.

23. Quick JC and Henderson DF. “Occupational stress: Preventing suffering, enhancing wellbeing". International Journal of Environmental Research and Public Health 13.5 (2016): 1-11.

24. Etikan I. "Developing questionnaire base on selection and designing". Biometrics and Biostatistics International Journal 5.6 (2017): 219-221.

Volume 5 Issue 8 August 2021

(C) All rights are reserved by Elena Ciobanu., et al. 